turn of duty has entire command of his ship. This gentleman is a complete colour-blind, and is still sailing as second mate. In justice to the steam-ship companies I must remark that they are unaware of his defect. I could mention other illustrative cases, but I have I think brought forward sufficient proof, not only of a danger that does exist, but also that adequate care is not taken, in the case of sailors, to guard against that danger. And the danger is no myth, though many are inclined to think that it is much exaggerated. The number of sailors in Liverpool has been calculated for me by Dr. Hope, the assistant medical officer of health, to be 27,136 . Taking 340 per cent.- the percentage found in the 3087 cases-to be colour-blind, we have a total of 922.99 men in that line of life who have not an accurate colour perception.

In a very able article ${ }^{1}$ Dr. Brailey points out that the regulation side lights on a vessel, the red and the green, should be recognised in clear weather at a distance of two miles, and that in the case of two vessels meeting at night, until therefore they are within two miles of each other, they can get no indication of their relative positions. That if the night is not clear or the lights badly trimmed, the distance at which the lights can be seen is greatly diminished. Supposing two steamers going at a rate of twelve miles an hour (the Holyhead boats travel at the rate of twenty), he points out that they would meet in five minutes, a short enough time for a course to be altered. If therefore there is any hesitation on the part of those in command, a calamity such as has recently occurred may take place. The subject is one that may be worked at by all, and one that would be found of interest by all, and as the medical profession have generally been the means of pointing out existing dangers, so in this case I expect it is only through them that this subject will attain the attention due to it.

\section{HAMATURIA FOLLOWED BY RETENTION OF URINE.}

BY HENRY GRAMSHAW, L.R.C.P.L., M.R.C.S.

E. $R$ - aged sixty-nine, of Lowestoft, a stout, fairly healthy-looking tradesman, called at my surgery to consult me on Sept. 5th, 1880. He complained of some difficulty in micturition at night, and remarked that the fluid he voided was dark in character, and somewhat diminished in quantity. I gave him a purgative, and prescribed a gallic acid mixture with henbane and infusion of buchu. $\mathrm{He}$ called again on the 7 th, bringing with him a bottle of coffee-ground-looking fluid, evidently urine, mixed with blood, and said he felt a little better, and rested longer at night, since taking the medicine. On the 9 th he called to say he was much better, and that the urine was almost clear again. On Friday, the $10 \mathrm{th}$, he presented himself with a less favourable report, and brought more urine, charged with blood, as before. He has been continuing his medicine, with the addition of some acetate of lead and opium pills, but without experiencing much benefit from it. He had rather imprudently taken a railway journey to Yarmouth on the Thursday, and sat up late; further on in the day he sent for me to visit him at his house, but being absent at the time, my assistant went, and, finding that the patient was unable to micturate, he passed a No. 8 gum-elastic catheter, and drew off about four ounces of bloody urine, which apparently afforded him much relief. This was at 5 o'clock. An hour later I saw him myself, and found him walking about the room in great distress. I passed a catheter, and drew off about a teacupful of bloody fluid. I tied the catheter into the bladder, and left him. Between 12 and 1 o'clock I was sent for again to see the patient, and my friend Mr. Clubbe kindly met me in consultation. We decided to give him a mixture containing opium and ergot, and to leave the catheter in situ; there was a small quantity of fluid oozing from it. On Saturday, the 11th, I found the patient had passed a tolerable night, with occasional sharp paroxysms of pain. The cloths and bedclothes were saturated with blood and urine, which had flowed down the catheter. I had them removed, and placed the end of the catheter into a glass bottle to ascertain the amount actually passing. At

4 Brit. Med. Journ., Nor. 24th, 1883. my mid-day visit I found that about eight ounces had escaped. I emptied the bottle, and replaced the catheter. About 9 o'clock the same evening Mr. Clubbe met me again. No urine had passed since my last visit, a space of eight hours, and we decided to withdraw the instrument, expecting it had got plugged, and to substitute a fresh one. We passed both gum elastic and silver prostatic catheters consecutively into the bladder, but no fluid came away, and we felt a little doubtful if by any chance a false passage had been made, though it did not appear so, as no difficulty was experienced with the catheter.

Not to be tedious, I will briefly say that during the next day (Sunday) Mr. Clubbe and I made several attempts to empty the bladder, but failed to do so, and we were a little surprised to find, as time passed on, that our patient's symptoms were not more urgent than they appeared to be, as the retention was complete. The pain, such as it was, he felt principally at the end of the penis, there being comparatively little about the vesical region. The grave aspect of affairs led us to deliberate on the next best mode of procedure; and we asked ourselves the question if it would be wise to proceed to puncture the bladder per rectum or otherwise. Having laid the facts before the relatives, I counselled them to allow me to telegraph for Mr. Cadge of Norwich to assist us with his opinion and advice in the emergency. Consent being given, that gentleman came over and saw the patient, with $\mathrm{Mr}$. Clubbe and myself, at half-past ten on Monday the 13th. Just before his arrival a little additional light was thrown on the care in consequence of the patient having passed in a clot of blood about twelve small calculi. The history of the case up to the present time having been laid before $\mathrm{Mr}$. Cadge, he at once gave it as his opinion that the patient's bladder was fully distended and blocked up with clotted blood, and that in all probability when catheterism was performed, the catheter went fairly into the bladder, piercing the blood-clot, which was too solid to flow down it. He said he was strongly averse to puncturing the bladder by the rectum in the case of an elderly, fat man, with prostatic enlargement, as it would probably be a procedure attended with no benefit, and, if need be, he should prefer either to puncture the bladder above the pubes or to aspirate itwhich latter might be considered a more new-fashioned plan of procedure; but before electing to undertake either operation, he would try what could be done per vias naturales-i.e., by the urethra itself.

Accordingly Mr. Cadge passed a No. 8 (with an unusually large eye), and afterwards a No. 10, into the bladder without much difficulty. A very little currant-jelly-like fluid escaped. After a long and most painstaking process of breaking up the clot in the catheter with a stilette, and gradually and judiciously forcing the clot down the catheter by firm and yet gentle pressure on the bladder, there was discharged a chamber utensil half full of clotted blood, mixed with ammoniacal-smelling urine, giving the patient substantial relief. The proceeding itself involved fully two hours of patient and skilled manipulation on the part of the operator, at the end of which time the patient fell back and slept comfortably for several hours. At 9 P.M. a similar process had to be repeated by Mr. Clubbe and myself.

Sept. 14th.-10.30 A.M.: Patient has had a very restless night; complains of more intolerance of the loaded bladder than he did previously. When the catheter is passed clot and thick treacly liquid comes at first, but little else; aided, however, by Clover's catheter with elastic suction-bottle, after first throwing into the bladder a little warm water, I got the patient to stand up, when a stream of bloody urine flowed down the catheter, amounting to twenty ounces or more. 8 P.M.: Used Clover's catheter again this evening. Patient passed more urine than he has yet done, and of a better colour and greater fluidity. There has also been free action of the bowels. The patient can take only milk. Gave him an opiate at night. -15 th : Patient better ; appetite returning. A considerable quantity of bloody urine withdrawn three times during the day by catheter. Ordered camphor and hyoscyamus, five grains of each, at bedtime, and to take the following three times a day: Solution of dilute sesquichloride of iron, twelve minims; water to one ounce. From this date the patient got slowly better, requiring catheterism three times a day for nearly a month, after which time he quite regained his usual health.

Remarks.-I have been tempted to give the details of this case rather fully, because it is the sort of case one might meet with any day in practice, and would always give the 
surgeon in attendance considerable anxiety. It also exemplifies the advantages of patience and perseverance. I gathered from Mr. Cadge's remarks that in all cases where retention of urine from the presence of a large quantity of clotted blood ix the bladder took place he would be disposed to temporise, believing sooner or later that the clot would liquefy and break down, and be removable by means of a good-sized large-eyed catheter.

Walton-on-the-Naze.

\section{THE SIGNIFICANCE AND TREATMENT OF CERTAIN FORMS OF ALBUMINURIA.}

\section{Br A. G. AULD, M.D.}

Acute Albuminuria.-Acute albuminuria or acute nephritis is a remarkable disease. Excepting its occurrence from the scarlatinal or other specific poison, it is in the great majority of cases ascribed to "cold and wet." Yet of a hundred cases of exposure to these agencies probably not more than one will be visited by this disease. Again, in scarlatina no adequate reasons can be given for its development in any particular case. It must therefore be confessed that its intrinsic causes are unknown; and not only so, but likewise the modus operandi of these causes $a b$ initio.

Looking, then, at the known facts, increase of arterial tension is the first observable symptom. Occasionally there is hæmoglobinuria. The invasion may take place insidiously, anattended with any constitutional disturbances perceptible to the subject, who may be suffering from debility; or sudden and fierce, giving rise to grave constitutional states. In the asthenic form, dropsy is usually the first symptom noticed by the patient if his attention be not previously drawn to the state of his urine. But, however established, uræmia is equally liable to supervene, and may even be the first symptom to give the alarm.

These modes of onset of this disease are not without parallel. For instance, it is known that acute pneumonia, though in the majority of instances having a sudden onset, may yet be creeping into a lung, and become pretty extensively established before the individual be sufficiently ill to think of leaving off work. There are also other striking points of resemblance in the natural histories of these diseases.

I suppose there is no disease of which it may be more truly said than of nephritis, that it spurns our artificial medication. Many persons pass safely through it without ever seeking medical aid; and when treated, if happily it should disappear, that result is of course by many set down in orthodox fashion to the particular remedy or remedies employed. It is not so very long since many highly respectable practitioners prescribed a course of mercury in this disease, and, mirabile dictu! very often with the result of a cure. It is a good thing that Nature still works as heretofore.

The eminent Sydenham, treating of the dropsy, remarks that the curative indications are to evacuate the water and to strengthen the blood. ${ }^{1}$ The first of these he fulfilled by speedy and smart purging, provided the patient was strong if of a weak habit, he found purgatives harmful, and resorted to diuretics and strengthening medicines. This mode of treatment was that generally adopted up to the time of Christison. Since then diuretics have fallen into comparative disuse, while the purgatives have been retained, which, together with hot baths, starvation diet, the imbibition of large quantities of water or other harmless fluid, and occasionally bleeding, form the cardinal measures now in use.

Unfortunately it has become the practice of many to adopt most or all of these heroic measures in every case of acute nephritis. It is said that diaphoretics and purgatives do the work of the kidney. That to some extent they do so cannot be gainsaid. They do produce a transient and superficial relief, but it is equally certain that their indiscriminate use is often productive of the greatest harm, especially if indulged in for any length of time. There are doubtless contingencies wherein one or other of these heroic measures are called for; where, namely, pyrexia runs high, where vascular tension overleaps the bounds of safety, where the march of uræmic symptoms is unchecked by the natural means, or where the advancing tide of cdema threatens to invade the vital organg. But each case is to be dealt with n its own merits, and the weakly will often quickly recover on tonic treatment, while irretrievable damage might be nflicted by any such exhausting processes as a course of purgatives and hot baths.

Whatever benefits are supposed to accrue from the energetic means so universally adopted, it is certain that physiologically they are antagonistic. The hot bath causes a great increase of the general blood-pressure and of the temperature, a bounding heart, with distended vessels and injected capillaries. Purgatives and antiphlogistics cause lowering of the blood-pressure and of the temperature and a depressed heart; while fluids imbibed in quantity heighten pressure and dilute the blood. I think, to pursue such a course of treatment can scarcely be justified on scientific grounds. Where is the rationale of placing cupping-glasses over the loins and then filling the kidneys with blood, of abstracting the water of the blood and then pouring water into it?

There is one of these agents, however, which must be discussed more in detail, and that is the hot bath. Senator has proved that when the temperature of an animal is raised by from $1.5^{\circ}$ to $3^{\circ} \mathrm{C}$. albuminuria results; and if the temperature be very rapidly raised to an extreme degree, blood and often hyaline and granular casts are present in the urine. ${ }^{2}$ Albuminuria also occurs in the human subject from a very high bodily temperature. The kidneys being greatly distended with blood, rupture of capillaries is liable to take place. Yet hot-water baths, sufficient to produce these effects in some measure, are employed for the cure of inflammation of the kidneys. The warm bath, with its many beneficial effects, is set aside in favour of baths which cause an enormous rapidity of the pulse-rate and respiration, and sustain a great height of temperature; indeed, lately a St. Petersburg physician for these very reasons strongly advocates the use of hot water in preference to hot air or wet packing. ${ }^{3}$ It is also an interesting fact that cases of scarlatinal albuminuria are most frequent during hot, relaxing weather, as the statistics of the London Fever Hospital show, and very frequently apparently healthy persons pass a little albumen in these circumstances. This being so, another method must be sought for the production of diaphoresis, and nothing is more admirably fitted for this purpose than the hypodermic injection of pilocarpine. Given in doses of from a quarter to a third of a grain, profuse diaphoresis is induced, without any vascular stimulation, but, on the other hand, with fall of tension. If, however, smaller doses are given, there is an initial stage of stimulation, which quickly passes off. Not only is this the best remedy for dropsy, but also for threatened uræmia and for uræmic convulsions, should purging prove ineffectual.

So far, then, as I have observed, I should prefer to adopt in the first instance a some what expectant plan of treatment in this affection. In the early stages, should no urgent symptom arise, small doses of aconite will suffice, with due attention to diet, which should be fairly nourishing and include abundance of milk. Should the disease threaten to become subacute, abundant nourishment, with cod-liver oil and iron, should be administered. I could relate several instances, some of them amusing, of patients who were kept in bed half starved, and steamed for weeks, with but little amelioration of their symptoms, who got up and returned to their usual diet and modes of living, and speedily recovered.

Acute albuminuria may terminate suddenly or gradually. Complete recovery may ensue after the dropsy has been six months or even a year established; and it may occur many times in the course of a life without causing any chronic affection of the kidneys. If, however, the disease should attack one who has got diseased bloodvessels, however slight, he can never perfectly recover.

Albuminuria of Debility.-If a medical man examines the urine of all who may consult him without reference to any disease of the kidney, he will frequently find albumen. In the majority of cases he will also be able to discover its cause. I wish to notice here the form of albuminuria associated with debility without any renal lesion. A great many cases of transient albuminuria and so-called cyclic albuminuria, which are variously ascribed to impure blood, slight congestions from cold, dyspepsia, nervousness, and other causes, also called albuminuria of adolescents, may shortly be said to be due to debility. In a strong person, a nervous

2 Senator on Albuminuria (New Sydenham Society), pp. 49-50.

3 THE LANCET, 1885, vol, ii., p. 1016 . 